\title{
Molecular networking-assisted flavonoid profile of Gypsophila glomerata extract in relation to its protective effects on carbon tetrachloride-induced hepatorenal damage in rats
}

\author{
BOJANA DIMITROVA 1,2 \\ RUMYANA VITANSKA ${ }^{1, *}$ \\ RENETA GEVRENOVA ${ }^{2}$ \\ DIMITRINA ZHELEVA-DIMITROVA \\ VESSELA BALABANOVA ${ }^{2}$ \\ STOYCHO STOEV ${ }^{3}$ \\ ${ }^{1}$ Department of Pharmacology \\ Pharmacotherapy and Toxicology \\ Faculty of Pharmacy, Medical University \\ of Sofia, 1000 Sofia \\ ${ }^{2}$ Department of Pharmacognosy and \\ Pharmaceutical Botany, Faculty of \\ Pharmacy, Medical University of Sofia \\ 1000 Sofia \\ ${ }^{3}$ Department of General and Clinical \\ Pathology, Faculty of Veterinary \\ Medicine, Trakia University, Students \\ Campus, 6000 Stara Zagora, Bulgaria
}

Accepted February 18, 2021

Published online March 6, 2021

\begin{abstract}
The aim of the study was to provide an in-depth characterization of the methanol-aqueous extract from the aerial parts of Gypsophila glomerata Pall. Ex Adams (Caryophyllaceae) (EGG) and to assess its protective potential on carbon tetrachloride $\left(\mathrm{CCl}_{4}\right)$-induced liver and kidney damage in male Wistar rats. Twenty-two flavonoid $\mathrm{C}_{-}, \mathrm{O}-$ and $\mathrm{C}, \mathrm{O}-$ -glycosides in EGG were annotated by mass spectrometry-based molecular networking; nine of them are reported in this species for the first time. Fourteen-day oral administration of EGG at a dose $200 \mathrm{mg} \mathrm{kg}^{-1} \mathrm{bm}$ prevented significantly $\mathrm{CCl}_{4}$-induced liver injury, discerned by an amelioration of the markers of oxidative stress (GSH and MDA) and transaminase activity. EGG decreased the serum level of urea and creatinine as well. The observed improvement of biochemical parameters was supported by histopathological observations. The protective hepatorenal effects of EGG, rich in 2"-O-pentosyl-6-C-hexosyl-apigenin/luteolin/ methylluteolin and their acetyl- and methoxycinnamoylderivatives, were comparable with the effects of the positive control silymarin.
\end{abstract}

Keywords: Gypsophila glomerata, $\mathrm{CCl}_{4}$, molecular network, hepatorenal toxicity, flavonoids

Nowadays, there is an increase in scientific interest in herbal medicines, since they could be a good natural alternative for synthetic drugs and a safe source of helpful substances and antioxidants, e.g., flavonoids, xanthones, terpenoids, although some concerns about their safety are also reported (1). It is well known that oxidative damage of DNA, lipids or proteins is associated with some chronic diseases (2) like hypertension, coronary diseases $(2,3)$, diabetes $(2,4)$ and cancer $(2,5)$. In the light of the above, the role of herbal drugs in the prevention or control of the aforementioned diseases is attributed mainly to the antioxidative effects of their constituents $(5,6)$.

Proven antioxidative properties $(7,8)$, as well as nephroprotective $(9,10)$, hepatoprotective and liver regenerative effects (11) along with anti-inflammatory, immunomodulatory

*Correspondence; e-mail address: rvitanska@gmail.com 
and membrane-stabilizing effects (12) were reported for different flavonoids, and especially for the flavolignan complex silymarin from Silybum marianum fruits, which was used as a positive control in this work.

The Gypsophila species are highly valued and important medicinal herbs widely spread in Asia and Europe, with application in traditional Chinese medicine to treat various ailments such as fever, malnutrition syndrome, diabetes (13), immune disorders or liver diseases (14-16). There are reports on the antioxidant potential of Gypsophila species related to C-flavonoid glycosides $(14,15,17,18)$. Our recent studies on some Gypsophila species revealed the protective effects of apigenin-O/C-diglucoside (saponarin) isolated from G. trichotoma against carbon tetrachloride $\left(\mathrm{CCl}_{4}\right)$ induced hepatotoxicity in vitro and in vivo in rats (19) or against paracetamol-induced liver damage (20) and cocaine-induced oxidative stress in rats (17); the protective effects were similar to that of silymarin. However, there is no information about the possible protective effect of the commonly found species, G. glomerata. Recently, a large number of triterpenoid saponins in G. glomerata roots was characterized (21). Eleven $\mathrm{C}$-glycosyl flavones and $4 \mathrm{O}$-glycosyl flavonoids, including 2"-O-pentosyl-6-C-hexosyl-apigenin/methylluteolin together with the common saponarin, homoorientin, orientin, isovitexin and vitexin were already reported in the aerial parts of $G$. glomerata (18). In addition, the total phenolic and flavonoid contents were determined to be $20.59 \mathrm{mg}$ gallic acid equivalent $\mathrm{g}^{-1}$ extract and $33.00 \mathrm{mg}$ rutin equivalent $\mathrm{g}^{-1}$ extract, resp. C,O-glycosyl flavones were commonly found in Gypsophila species (18, 22-24). 2"-O-arabinosyl/rhamnosyl/glucosyl-6/8-C-hexosyl-derivatives of apigenin, luteolin and methylluteolin were reported in G. paniculata, G. elegans and G. pacifica. Recently, a variety of $C$ - and di-C-glycosyl flavones were evidenced in G. perfoliata, while acetylated C,O-glycosyl flavones were annotated only in G. glomerata (18). These investigations highlight the importance of the aerial parts of the Gypsophila species as a new source of bioactive agents, e.g., antioxidants, acetylcholinesterase and $\alpha$-glucosidase inhibitors. Furthermore, it has been reported that the extracts of G. glomerata possessed promising radical scavenging activity, reducing ability and metal chelating activity in the in vitro antioxidant assays (18).

Hence, the aim of the present study was to explore the possible protective effect of $G$. glomerata on $\mathrm{CCl}_{4}$-induced damages in the liver and kidneys in rats and to compare these beneficial effects with the well-known effect of silymarin. In addition, molecular network-assisted flavonoid profiling of G. glomerata extract in relation to its beneficial properties was performed.

\section{EXPERIMENTAL}

\section{Plant material and extract preparation}

G. glomerata aerial parts were collected in September 2010, at Ognyanovo village (Pazardjik region, Bulgaria) $\left(42^{\circ} 15^{\prime} \mathrm{N}-24^{\circ} 42^{\prime}\right.$ E). The plants were identified by Dr. R. Gevrenova (Faculty of Pharmacy, Medical University-Sofia, Bulgaria). Voucher specimens were deposited at the Institute of Biodiversity and Ecosystems Research, Bulgarian Academy of Sciences, Sofia, Bulgaria (SOM 171499).

Air-dried powdered aerial parts (leaves, stems and flowers) were extracted with $80 \%$ methanol (1:25, solid/solvent) $(\times 3)$ by sonication for $15 \mathrm{~min}$ (each time) at room temperature and lyophilized to yield the crude extract (EGG). 


\section{Chemicals}

Acetonitrile (hypergrade for LC-MS), formic acid (HPLC grade) and methanol (analytical grade) were purchased from Merck (Germany). The standards of orientin, homoorientin, vitexin, isovitexin, kaempferol 3-glucoside (astragalin) ( $\geq 99 \%$ HPLC purity), saponarin and kaempferol-3-rutinoside ( $\geq 98 \%$ HPLC purity were provided from Extrasynthese (France).

\section{Animals}

The rats were housed, maintained and euthanized in accordance with the relevant international rules and recommendations as stated in the European Convention for the Protection of Vertebrate Animals used for Experimental and other Scientific Purposes (ETS 123) (25). The Animal Care Ethics Committee approved the study protocol and Ethics clearance (No 273 from 02/07/2020) was issued for the study by the Bulgarian Agency for Food Safety.

Thirty-six specific pathogen-free male Wistar rats, three months old (150-200 g) were used. The rats were housed in plexiglass cages ( 3 per cage) in a 12/12 light/ dark cycle, under standard laboratory conditions (ambient temperature $20 \pm 2{ }^{\circ} \mathrm{C}$ and humidity $72 \pm 4 \%$ ). Animals were purchased from the National Breeding Center, Sofia, Bulgaria. A minimum of 7 days of acclimatization was allowed before the commencement of the study. The standard complete commercial pelleted rat feed suitable for their age and fresh drinking water were available ad libitum during the entire experimental period of 14 days.

\section{Experimental design and outcome}

Male Wistar rats were randomized into six experimental groups with six animals in each. Carbon tetrachloride, G. glomerata extract and silymarin were administered per os via oral gavage using a feeding needle as follows: group 1 (control animals) were treated with physiological saline $\left(0.5 \mathrm{~mL} \mathrm{~g}^{-1} \mathrm{bm}\right)$, group 2 rats were treated with silymarin alone solubilized with Tween $80(0.1 \%)$ in a physiological saline buffer $\left(100 \mathrm{mg} \mathrm{kg}^{-1}\right.$ per day, for 14 days) (26), group 3 was orally administered with EGG alone dissolved in a physiological saline buffer (200 $\mathrm{mg} \mathrm{kg}^{-1}$ per day, for 14 days), group 4 received a single oral dose of $10 \%$ $\mathrm{CCl}_{4}$ in olive oil $\left(1.25 \mathrm{~mL} \mathrm{~kg}^{-1}\right)$ (27) at day 7, group 5 animals were treated with silymarin $\left(100 \mathrm{mg} \mathrm{kg}^{-1}\right)$ for 7 days and on day 7 the animals were challenged with $\mathrm{CCl}_{4}(10 \%$ solution) and subsequently treated with silymarin $\left(100 \mathrm{mg} \mathrm{kg}^{-1}\right)$ for another 7 days; group 6 was pre-treated for 7 days with EGG (200 mg kg-1 $)$, intoxicated with $10 \% \mathrm{CCl}_{4}$ solution at $7^{\text {th }}$ day, and additionally treated with EGG $\left(\mathrm{mg} \mathrm{kg}^{-1}\right)$ for another 7 days.

On the $15^{\text {th }}$ day, the animals were euthanized using $\mathrm{CO}_{2}$, then sacrificed with a laboratory guillotine in strict accordance with the rule of the Animal Ethics Committee and adopted Directive 2010/63/EU (28). Blood for serum biochemical investigations was collected in tubes containing a clot activator. After centrifugation at $3000 \times g$ for $10 \mathrm{~min}$, the serum was separated. Afterward, the livers and kidneys were taken to assess the oxidative stress biomarkers - MDA, GSH. For all following experiments, the excised organs were perfused with cold saline solution $(0.9 \% \mathrm{NaCl})$, blotted dry, weighed and homogenized with appropriate buffers. Small pieces of livers and kidneys from all rats were preserved in $10 \%$ neutral buffered formalin for histopathological assessment. 


\section{UHPLC-ESI/HRMS}

The LC-MS analyses were performed on a Q Exactive Plus heated electrospray ionization (HESI-II) - high-resolution mass spectrometer (HRMS) (Thermo Fisher Scientific, USA) equipped with an ultra high-performance liquid chromatography (UHPLC) system Dionex Ultimate 3000RSLC (Thermo Fisher Scientific). The UHPLC separation and mass spectrometry conditions were reported elsewhere (18). Briefly, the mass spectrometer was operated in negative ion mode with the HESI source of $2.5 \mathrm{kV}$ and capillary temperature of $320^{\circ} \mathrm{C}$. The mass analyzer scanned over a mass range of $100-1500 \mathrm{~m} / \mathrm{z}$ in Full MS-ddMS $/$ Top 5 scan type, $2 \mathrm{~m} / \mathrm{z}$ quadrupole isolation window of precursor ions, higher energy collision-induced dissociation (hcd) was set at 25. The UHPLC separations were performed on a Kromasil EternityXT C18, $1.8 \mu \mathrm{m}, 2.1 \times 100 \mathrm{~mm}$ (AkzoNobel, Sweden). The binary mobile phase consisted of A: $0.1 \% \mathrm{HCOOH}$ and $\mathrm{B}: 0.1 \% \mathrm{HCOOH}$ in acetonitrile. The following step gradient profile was used: $5 \% \mathrm{~B}$ for $1.0 \mathrm{~min}$, increased linearly to $25 \% \mathrm{~B}$ in $14 \mathrm{~min}$, held isocratic at $25 \% \mathrm{~B}$ for $2.0 \mathrm{~min}$, increased linearly to $50 \% \mathrm{~B}$ in $1.0 \mathrm{~min}$, held isocratic at $50 \%$ B for $2.0 \mathrm{~min}$, increased linearly to $95 \%$ B in $2.0 \mathrm{~min}$, held isocratic for $2.0 \mathrm{~min}$, finally brought back down to $5 \% \mathrm{~B}$ over $0.5 \mathrm{~min}$. The flow was $0.3 \mathrm{~mL} \mathrm{~min}{ }^{-1}$. Data were processed with Xcalibur software ver. 3.0 (Thermo Scientific). The calculation of the exact masses and mass measurement errors and prediction of molecular formulas were carried out with Xcalibur software.

\section{Molecular networking}

The method of molecular networking (MN) was applied to improve the annotation and dereplication of the chromatographic peaks (29). MN was created using the GNPS platform (Global Natural Product Social Molecular Networking) (30). Generally, MN displays fragmentation similarities between metabolites in complex plant matrices via the establishment of a cosine score. The principle of $\mathrm{MN}$ is that the metabolites sharing similar fragmentation patterns are usually structurally correlated. Thus, precursor ions of different molecules but belonging to a common structural type are grouped in clusters. Within the cluster, each node corresponds to a consensus MS/MS spectrum; nodes with related fragmentation patterns are connected with edges reflecting the mass differences between the associated ions. MN allows for a visual molecular map by linking the nodes regarding the similarity score (cosine score) of their associated MS/MS data.

The first step in G. glomerata MN assessment consisted in the cluster discovery with $\mathrm{C}$ - and $\mathrm{C}, \mathrm{O}$-flavonoid glycosides. MN generated 3 clusters (A, B, C) allowing visual examination of the consequent flavonoid structural types and facilitated their annotation. In the second step, the dereplication of some compounds was achieved by the GNPS library. Finally, the extracted ion chromatograms were used to verify and annotate isobaric structures.

Raw file in the negative ion mode was uploaded to the GNPS online platform where the molecular networking was generated with online workflow (30).

\section{Animal physical activity and gross pathology}

During the experimental period the housing-related activity (walking, running, climbing, rearing, passivity, fighting, eating and social behaviors), food and water quan- 
tity intake were surveilled daily by veterinary. Reactions of animals to "external stimuli" (response to handling, righting reflex, response to hand clapping, response to noise, response to light fluctuations, toe or tail pinch reflex) were assessed.

\section{Blood biochemical assays and oxidative stress markers}

AST, ALT, urea and creatinine in the serum were assessed using commercially available standard diagnostic kits (Mindray, China) with an automatic biochemistry analyzer (BS-120, Mindray).

Oxidative damage was determined by measuring the quantity of thiobarbituric acid reactive substances (TBARS), expressed as malondialdehyde (MDA) equivalents as described by Polizio and Peña (31). Reduced glutathione (GSH) was assessed by measuring the non-protein sulfhydryls after precipitation of proteins with trichloroacetic acid (TCA), using the method described by Bump (32).

\section{Pathomorphological examination}

On the day of euthanasia (day 15), materials were taken from the kidneys and liver of all experimental and control animals for histological examination. These were fixed in $10 \%$ neutral buffered formalin. The fixed tissues were processed for paraffin embedding, sectioned at $6 \mu \mathrm{m}$ and stained with haematoxylin-eosin. Histological changes were observed and photo-documented with a light microscope with a built-in camera Leica (Germany).

\section{Statistical methods}

Statistical analysis was performed using the MEDCALC program. Results are expressed as mean $\pm S D$ for six rats in each group. Experimental groups were compared by the Kruskal-Wallis variance analysis test, and a post-hoc analysis using the Mann-Whitney $U$ test was performed. Statistical significance was considered at $p \leq 0.05$.

\section{RESULTS AND DISCUSSION}

\section{Molecular networking-based annotation of G. glomerata flavonoids}

Herein, non-targeted metabolic profiling of G. glomerata extract was performed by UHPLC-HRMS (Fig. SI). Putative flavonoid annotation was based on the high accuracy MS and dd-MS ${ }^{2}$ data, molecular formula and fragmentation pattern in comparison with the previously reported data (18), assisted by the MN investigation and GNPS spectral library search. Our approach for flavonoid structural elucidation was based on the diagnostic fragment ions for $\mathrm{O}_{-}, \mathrm{C}$ - and $\mathrm{C}, \mathrm{O}$-glycosides in Gypsophila species and reference standards (18). The main criteria in the peak annotation of flavonoid glycosides were the neutral losses of 132.042, 162.053 and 176.033 Da consistent with pentose, hexose and hexuronic acid units. The characteristic retro-Diels-Alder (RDA) cleavages of the flavonoid backbone $\left({ }^{1,3} \mathrm{~B}^{-},{ }^{1,3} \mathrm{~A}^{-}\right)$supported by a series of fragment ions arising from the neutral losses of $\mathrm{H}_{2} \mathrm{O}$ (-18), $\mathrm{CO}(-28), \mathrm{CH}_{2} \mathrm{O}(-30), \mathrm{CO}_{2}(-44), \mathrm{CO}+\mathrm{C}_{2} \mathrm{HO}_{2}(-85), \mathrm{CH}_{2} \mathrm{O}_{2}(-46)$ and radical losses $\cdot \mathrm{CH}_{3}(-15)$ and $\bullet \mathrm{HCO}(-29)$, were used for the aglycone annotation $(18,33)$. The fragmenta- 
tion of the $C$-hexosides affords diagnostic cross ring cleavages of the sugar moieties as follows: ${ }^{0,1} X_{0}(-150),{ }^{0,2} X_{0}(-120),{ }^{0,3} X_{0}(-90),{ }^{0,4} X_{0}(-60)$. The rules for the recognition of $6-C$ and 8 -C glycosyl flavone isomers were described elsewhere (18). In addition, the acetyl (Ac) and methoxycinnamoyl (MeCin) groups are evidenced by the losses of $\mathrm{Ac}(-42), \mathrm{AcOH}(-60)$, MeCin (-178). Further, the created MN allowed for the visualisation of the related derivatives and facilitated the annotation of the $C$-flavonoids. The mass difference $(\Delta m / z)$ between the compounds in each pair underlies a structure modification. For instance, the difference of 30.01 Da usually resulted from the aglycone structure - apigenin/methylluteolin, while 84.023 Da was diagnostic for diacetylated descendants. Diacetylated and methoxycinnamoyl-acetyl-derivatives were connected together with $\Delta m / z 136.052 \mathrm{Da}$; $\Delta m / z 220.075 \mathrm{Da}$ indicated additional Ac and MeCin groups.

Within cluster A, the negative networking using MS/MS spectra allowed for the dereplication of one flavonoid with deprotonated molecule [M-H $]^{-}$at $m / z 563.140$ by GNPS spectral library search as 2"-O-pentosyl-isovitexin (1), previously reported in G. glomerata (18) (Table SI, Fig. 1).

In (-)ESI-MS/MS compound 1 gave an intensive fragment ion at $m / z 413.088$ [(M-H)$\left.132-\mathrm{H}_{2} \mathrm{O}\right]^{-}\left(\mathrm{Z}_{1}^{-}\right)(45.3 \%)$ together with ion at $\mathrm{m} / \mathrm{z} 293.045\left[(\mathrm{M}-\mathrm{H})-\left(132+\mathrm{H}_{2} \mathrm{O}\right)-120\right]^{-}\left(\mathrm{Z}_{1}^{-} / 0,2 \mathrm{X}_{0}\right)$ $(96.5 \%)$ indicating $O$-glycosylation in a 6-C-hexosyl unit.

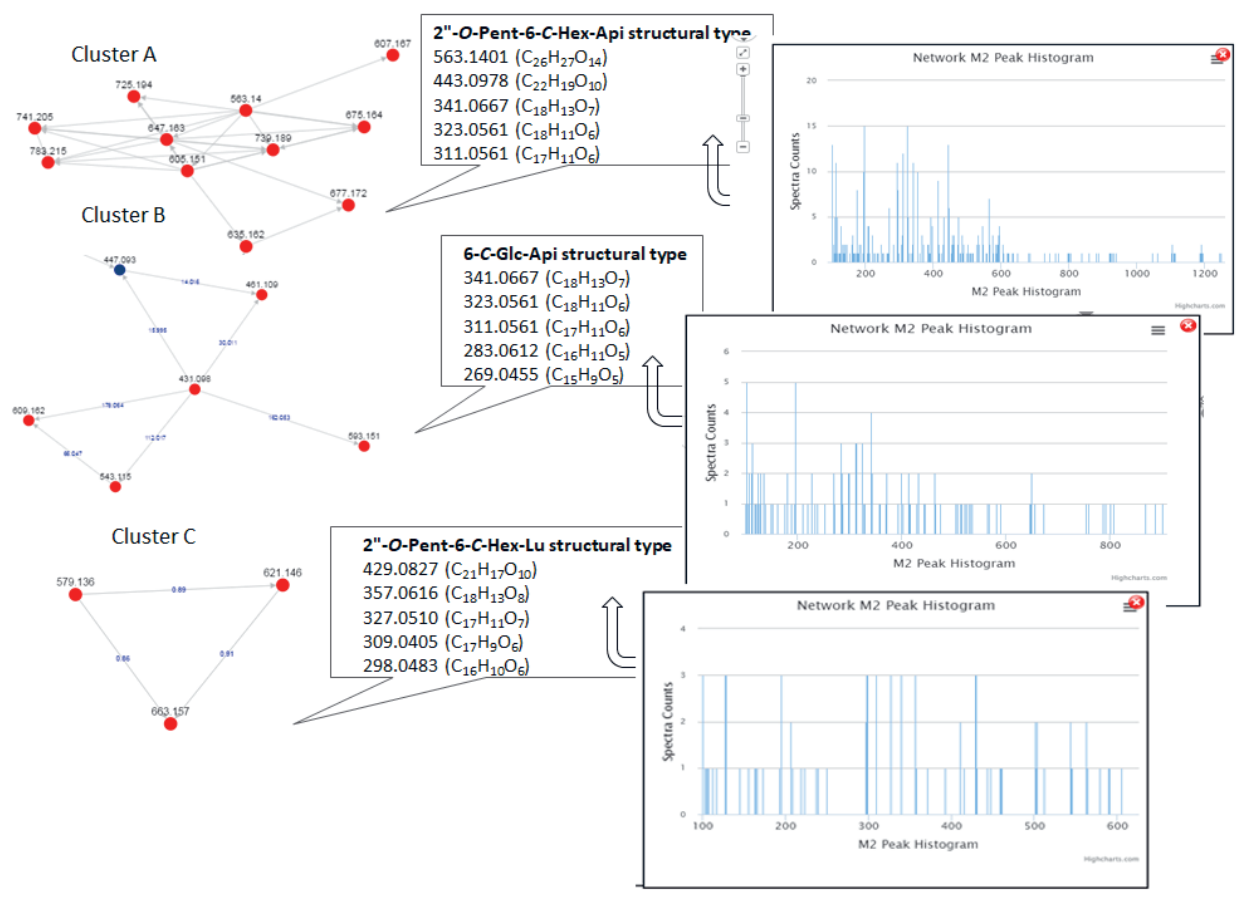

Fig. 1. Diagnostic fragment ions in (-)ESI-MS/MS of the studied clusters consisting of flavonoids from G. glomerata extract created in the GNPS platform. 
Compound $2\left([\mathrm{M}-\mathrm{H}]^{-}\right.$at $m / z$ 605.151) coinciding with a molecular formula $\mathrm{C}_{28} \mathrm{H}_{29} \mathrm{O}_{15}$, was directly connected with 1 with $\Delta m / z 42 \mathrm{Da}$; it could be envisioned as its acetylated derivative. In addition, considering the observed $\Delta m / z$, compound 3 at $m / z 647.162$ corresponding to a formula $\mathrm{C}_{30} \mathrm{H}_{32} \mathrm{O}_{16}$ could be associated with the formerly annotated diacetylated derivative of $\mathbf{1}$.

The linkages between 1 and $4\left([\mathrm{M}-\mathrm{H}]^{-}\right.$at $m / z$ 739.182) and $5(m / z 741.204)$ by $\Delta m / z$ of $176.049\left(\mathrm{C}_{6} \mathrm{H}_{8} \mathrm{O}_{6}\right)$ and $178.065\left(\mathrm{C}_{10} \mathrm{H}_{10} \mathrm{O}_{3}\right)$, indicated their assignment as $\mathrm{O}$-hexuronosyl- $\left(2^{\prime \prime}-\right.$ -O-pentosyl)-isovitexin and 2"-O-(methoxycinnamoylpentosyl)-isovitexin, resp. (Table SI, Fig. 1). Moreover, the extracted ion chromatograms confirmed the peak annotation by the fragment ions at $m / z 293.046\left[(\mathrm{M}-\mathrm{H})-176-\left(132+\mathrm{H}_{2} \mathrm{O}\right)-120\right]^{-}$(base peak, $\left.100 \%\right)\left(\mathrm{Z}_{1}^{-} / 0,2 \mathrm{X}_{0}\right)(4)$ and

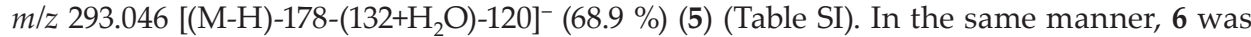
ascribed to O-hexosyl-(2"-O-pentosyl)-isovitexin evidenced by the abundant ions at $\mathrm{m} / \mathrm{z}$ 563.140 [(M-H)-162 $]^{-}\left(\mathrm{O}\right.$-glycosylation) and $\mathrm{m} / \mathrm{z} 293.046\left[(\mathrm{M}-\mathrm{H})-162-\left(132+\mathrm{H}_{2} \mathrm{O}\right)-120\right]^{-}(\mathrm{O}-$ glycosylation in the $C$-linked hexose) (Table SI). Compound 6 could be associated with $O$-hexosyl-2"-O-pentosyl-6(8)-C-hexosyl-apigenin previously reported in G. paniculata and G. repens $(31,34)$.

Consistent with the aforementioned assumptions, 7 was ascribed as an acetyl-methoxycinnamoyl derivative of $\mathbf{1}$ (Table SI, Fig. 1).

The direct attachment of 2 to 8 with $\Delta m / z 30.011 \mathrm{Da}$, together with the characteristic fragment ions at $\mathrm{m} / \mathrm{z} 443.098\left[(\mathrm{M}-\mathrm{H})-\left(132+\mathrm{H}_{2} \mathrm{O}\right)-\mathrm{Ac}^{-}\left(\mathrm{Z}_{1}^{-}\right)(43.5 \%)\right.$ and $323.056[(\mathrm{M}-\mathrm{H})-$ $\left(132+\mathrm{H}_{2} \mathrm{O}\right)$-Ac- 120$]^{-}\left(\mathrm{Z}_{1}^{-} / 0,2 \mathrm{X}_{0}\right)(85.4 \%)$ indicated acetylated 2"-O-pentosyl-6-C-hexosyl-flavone. The manual examination of the comparative MS/MS spectra showed a typical fragmentation behavior of 2 with a constant shift of $30 \mathrm{Da}, 293 / 323\left(\mathrm{Z}_{1}^{-} / 0,2 \mathrm{X}_{0}\right), 311 / 341\left(\mathrm{Y}_{1}{ }^{-10,2} \mathrm{X}_{0}\right)$ allowing allocation of the additional $30 \mathrm{Da}$ on the aglycone. In contrast to the apigeninderivatives, the precursor ion of 8 afforded diagnostic ions at $m / z 308.033\left[\mathrm{Y}_{1}{ }^{0,2} \mathrm{X}_{0}-\mathrm{CH}_{3}\right]^{-}$, $294.050\left[\mathrm{Y}_{1} /{ }^{0,2} \mathrm{X}_{0}-\mathrm{CH}_{3}-\mathrm{CHO}^{-}, \mathrm{m} / \mathrm{z} 293.044\left[\mathrm{Y}_{1}{ }^{0,2} \mathrm{X}_{0}-\mathrm{CH}_{3}-\mathrm{CH}_{2} \mathrm{O}\right]^{-}\right.$and $133.028\left[^{1,3} \mathrm{~B}\right]^{-}$indicating methylluteolin (18). Thus, 8 was annotated as 2"-O-(acetylpentosyl)-6-C-hexosyl-methylluteolin. Within the same cluster, compound 9 with $[\mathrm{M}-\mathrm{H}]^{-}$at $\mathrm{m} / \mathrm{z} 677.172$ was closely related to 8 with $\Delta m / z$ difference of $42.011 \mathrm{Da}$, indicating one supplementary acetyl group (Table SI, Fig. 1).

It should be noted that according to the cosine score histogram, high cosine scores were registered (0.86-0.94) for the discussed pairs of compounds (Fig. 1). Within cluster A, eight flavonoids are structurally related to 1 . It's worth noting that it was linked to most of the constituting nodes. It was connected to 2 with $\Delta m / z 42 \mathrm{Da}$, to 8 with $\Delta m / z 84 \mathrm{Da}$, to 4 with $\Delta m / z 176 \mathrm{Da}$, to 6 with $\Delta m / z 162 \mathrm{Da}$, etc. (Fig. 1). It appeared as a main ion within cluster A. Thus, cluster A could be ascribed as 2"-O-pentosyl-isovitexin structural type. As visible from the Table SI and MS/MS histogram, the fragment ion at $\mathrm{m} / z 563\left([\mathrm{M}-\mathrm{H}]^{-}\right.$of $\left.\mathbf{1}\right)$ was registered in 7 fragment spectra, $m / z 443\left[(\mathrm{M}-\mathrm{H})^{-0,2} \mathrm{X}_{0}\right]^{-}$in 13 spectra, $m / z 341\left(\mathrm{Y}_{1}^{-} / 0,3 \mathrm{X}_{0}\right)$ in 11, $\mathrm{m} / \mathrm{z} 323\left(\mathrm{Z}_{1}^{-} / 0,3 \mathrm{X}_{0}\right)$ in 15, $\mathrm{m} / \mathrm{z} 311\left[(\mathrm{M}-\mathrm{H})^{-}{ }^{0,3} \mathrm{X}_{1}-\mathrm{Pent}\right]^{-}\left(\mathrm{Y}_{1}^{-} / 0,2 \mathrm{X}_{0}\right)$ in 12, and $\mathrm{m} / \mathrm{z} 269$ [apigenin-H] $]^{-}$in 6 spectra.

Within the second cluster, B, consisting of six nodes, three compounds were dereplicated by GNPS spectral library search with precursor ions at $m / z 431.098$ - isovitexin (10), $m / z 447.093$ - homoorientin (12) and $m / z 593.151$ - saponarin (15) (Fig. 1). The extracted ion chromatograms showed the presence of three isobars at $\mathrm{m} / \mathrm{z} 447.093$. In addition to homoorientin (6-C-glucosyl-luteolin), luteolin-7-glucoside (13) and kaempferol-3-glucoside (14) were evidenced as well (Table SI, Fig. 1); all of them were reported earlier (18). Isovitexin 
(6-C-glucosyl-apigenin) (10) at $m / z 431.098$ was connected to 12 with $\Delta m / z$ of $15.995 \mathrm{Da}(O)$. Furthermore, extracted ion chromatogram at $\mathrm{m} / \mathrm{z} 431$ showed the presence of isovitexin and its isomer vitexin (8-C-glucosyl-apigenin) (11), formerly identified in G. glomerata (18). Key points of recognition of $6-C$ - and $8-C$-glucosyl-apigenin/luteolin are relative abundances of the diagnostic ions $[\mathrm{M}-\mathrm{H}]^{-},{ }^{0,3} \mathrm{X}^{-},{ }^{0,2} \mathrm{X}^{-},{ }^{0,2} \mathrm{X}^{-} / \mathrm{CO}$.

Manual examination of the MS/MS spectra of a precursor ion at $m / z 593.151$ revealed that along with saponarin (15), two previously annotated isobars 2"-O-pentosyl-6-C-hexosyl-methylluteolin (16) and kaempferol 3-rutinoside (17) were evidenced (Table SI, Fig. 1). In (-)ESI-MS/MS 16 afforded diagnostic fragment ions at $m / z 323.056$ [(M-H)- $\left.\left(132+\mathrm{H}_{2} \mathrm{O}\right)-120\right]^{-}$ $\left(\left[\mathrm{Z}_{1}{ }^{0,2} \mathrm{X}_{0}\right]^{-}\right)$indicating $2^{\prime \prime}$-O-pentosyl and $C$-hexosyl moieties as was seen in 1 . The aglycone was discerned by the ions at $m / z 308.033\left(\mathrm{Z}_{1}^{-} / 0,2 \mathrm{X}_{0} / \mathrm{CH}_{3}\right), m / z 299.055[\mathrm{MeLu}-\mathrm{H}]^{-}, m / z 280.0377$ $\left(\mathrm{Z}_{1}{ }^{-} / 0,2 \mathrm{X}_{0} / \mathrm{CH}_{3} / \mathrm{CO}\right)$ and $\mathrm{m} / \mathrm{z} 269.045\left[\mathrm{MeLu}-\mathrm{H}-\mathrm{CH}_{2} \mathrm{O}\right]^{-}$relevant for the methoxy group and methylluteolin. Regarding 17, the fragment ion at $m / z 285.040$ resulting from the concomitant loss of hexose and deoxyhexose units (308 Da) and relative abundance of $96 \%$ led to its assignment as $\mathrm{O}$-glycoside; kaempferol-3-rutinoside was additionally confirmed by comparison with an authentic standard.

Precursor ion at $m / z 461.109$ (18) was attached to 12 and 11 with $\Delta m / z$ of $14.016 \mathrm{Da}\left(\mathrm{CH}_{2}\right)$ and $30.011\left(\mathrm{OCH}_{2}\right)$, resp. According to the previously established relative abundances of diagnostic ions for 6-/8-C-glucosyl-flavones, fragment ions at $m / z 371.078{ }^{0,3} \mathrm{X}^{-}(26 \%), \mathrm{m} / \mathrm{z}$ $341.067^{0,2} \mathrm{X}^{-}(84 \%)$ and $\mathrm{m} / \mathrm{z} 298.048^{0,2} \mathrm{X}^{-} / \mathrm{CH}_{3} / \mathrm{CO}(54 \%)$ indicated 6-C-hexosyl flavone. A series of ions resulting from the neutral and methyl radical losses from ${ }^{0,2} \mathrm{X}$ at $\mathrm{m} / \mathrm{z} 298.048$, $269.045\left({ }^{0,2} \mathrm{X}^{-} / \mathrm{CH}_{3} / \mathrm{C}_{2} \mathrm{HO}_{2}\right), 241.051\left({ }^{0,2} \mathrm{X}^{-} / \mathrm{CH}_{3} / \mathrm{C}_{2} \mathrm{HO}_{2} / \mathrm{CO}\right), 225.055\left({ }^{0,2} \mathrm{X}^{-} / \mathrm{CH}_{3} / \mathrm{C}_{2} \mathrm{HO}_{2} / \mathrm{CO} /\right.$ $\mathrm{CO}_{2}$ ) are indicative for 6-C-hexosyl-methylluteolin. Precursor ion at $\mathrm{m} / \mathrm{z} 609.161$ (19) was linked to 10 by $\Delta m / z$ of 178.064 Da suggesting methoxycinnamoyl ester of 6-C-hexosylapigenin. Within cluster B, flavonoids were depicted as structurally related congeners of 10, and the cluster could be ascribed to isovitexin structural type.

Cluster $\mathrm{C}$ has three closely related nodes in the spectral networking assuming their peculiar fragmentation (Fig. 1). They are tentatively ascribed to 2"-O-pentosyl-6-C-hexosyl-luteolin (20) and its mono- (21) and diacetylated (22) derivatives. The MS/MS histogram of the cluster $\mathrm{C}$ showed a series of diagnostic ions at $m / z 298.048\left(\mathrm{Y}_{1}^{-} /{ }^{0,2} \mathrm{X}_{0} / \mathrm{CHO}, \mathrm{C}_{16} \mathrm{H}_{10} \mathrm{O}_{6}\right)$, $309.041\left(\mathrm{Z}_{1}^{-} /^{0,2} \mathrm{X}_{0}, \mathrm{C}_{17} \mathrm{H}_{9} \mathrm{O}_{6}\right), 327.051\left(\mathrm{Y}_{1}^{-} /^{0,2} \mathrm{X}_{0}, \mathrm{C}_{17} \mathrm{H}_{11} \mathrm{O}_{7}\right), 339.051\left(\mathrm{Z}_{1}^{-} / 0,3 \mathrm{X}_{0}, \mathrm{C}_{18} \mathrm{H}_{11} \mathrm{O}_{7}\right), 357.062$ $\left(\mathrm{Y}_{1}^{-} / 0,3 \mathrm{X}_{0}, \mathrm{C}_{18} \mathrm{H}_{13} \mathrm{O}_{8}\right), 411.072\left(\mathrm{Z}_{1}^{-} / \mathrm{H}_{2} \mathrm{O}, \mathrm{C}_{21} \mathrm{H}_{15} \mathrm{O}_{9}\right), 429.083\left(\mathrm{Z}_{1}^{-}, \mathrm{C}_{21} \mathrm{H}_{17} \mathrm{O}_{10}\right)$ (Table SI). Consequently, the cluster was assessed as 2"-O-pentosyl-6-C-hexosyl-luteolin structural type.

In total, twenty-two flavonoids belonging to $\mathrm{C}, \mathrm{C}, \mathrm{O}-$, and $\mathrm{O}$-glycosides were dereplicated or tentatively annotated in the G. glomerata extract by the means of molecular networking and in-deep ESI-MS/MS characterization of the compounds.

The main finding of this study is that nine flavonoids, namely, 4, 5, 7, 9, 18-22 were reported for the first time in the genus Gypsophila. This is the first report on the annotation of compounds 4-7, 18, 19, 21 and 22 in G. glomerata. All of them are structurally related flavonoids, especially $\mathrm{C}, \mathrm{O}$-glycosides with supplementary acetyl and methoxycinnamoyl moieties. It's worth noting that based on the detailed analysis of MS/MS data and MS/MS histograms, a series of relevant ions for each of the defined clusters is outlined (Fig. 1). The chromatographic profile of the EGG was dominated by 2"-O-pentosyl-6-C-hexosyl-apigenin/ luteolin/methylluteolin $(\mathbf{1}, \mathbf{1 6}, \mathbf{2 0})$ and diacetylated derivative 3 (Fig. SI). 


\section{Animal physical activity and gross pathology}

During the 14 days of the investigational period, no mortality was observed in the experimental and control rats. The physical activity level in $\mathrm{CCl}_{4}$-treated rats from group 4 had decreased, as assessed by their reduced response to external stimuli. In this group, food and water intake also decreased. The abdomens of these animals were slightly swollen. All other groups were recorded as having normal activity levels and with normal intake of food and water during the whole experimental period.

\section{Biochemical findings}

The effects on lipid peroxidation and GSH levels in rats with induced $\mathrm{CCl}_{4}$ intoxication are shown in Fig. 2.

Compared to the respective control group, $\mathrm{CCl}_{4}$ toxicity was presented by an increased amount of MDA (by $55 \%, p<0.05$ ) and decreased levels of GSH both in the liver and kidney tissues (by $25 \%$ and $32 \%$, resp., $p<0.05$ ). $\mathrm{CCl}_{4}$ possesses strong hepatotoxic and nephrotoxic properties $(34,35)$. The liver and kidney damages induced by $\mathrm{CCl}_{4}$ are obviously due to the formation of reactive intermediates which are responsible for the subsequent lipid peroxidation of membrane lipids leading to membrane disintegration of hepatocytes and leakage of the enzymes into the serum (36). Enzyme biomarkers of hepatotoxicity AST and ALT were increased by 133 and $46 \%$, resp. $(p<0.05)$ in $\mathrm{CCl}_{4}$ alone treated group in the current study (Figs. 3a,b). In a model of liver fibrosis induced by $\mathrm{CCl}_{4}$ Lin and co-workers (15) found similar changes in hepatic biochemical parameters as we found in the toxic model group.

These $\mathrm{CCl}_{4}$-generated free radicals could also damage kidney function $(37,38)$. In the present investigation this toxicity was evidenced by the statistically significant increase in serum urea and creatinine levels of 176 and $99 \%$, resp., compared to the controls (Figs. $3 c, d)$. A higher serum level of creatinine can be attributed to the damaged structure of the nephron.

EGG treatment reduced the $\mathrm{CCl}_{4}$-induced toxicity in the liver by inhibiting lipid peroxidation and restoring the levels of cell GSH. By comparing the data obtained from the EGG $+\mathrm{CCl}_{4}$-group vs. the $\mathrm{CCl}_{4}$-alone group, a significant decrease in MDA quantity by $21 \%$ $(p<0.05)$ and an increase in GSH by $46 \%(p<0.05)$ were observed. These changes were less evidenced in the kidneys (Fig. 2). Seven-day pre-treatment with the silymarin and EGG was used to prevent lipid peroxidation and to stabilize cell membranes in order to limit and attenuate the toxic effects of $\mathrm{CCl}_{4}$. Probably this prophylactic effect synergistically complements the subsequent protective effect after intoxication and helps to overcome the liver and kidney damage.

EGG and silymarin treatments which were administered separately did not significantly affect the serum biochemical markers, except for the activity of ALT which had decreased by $19 \%$ using silymarin, compared to the negative control $(p<0.05)$.

Administration of EGG in $\mathrm{CCl}_{4}$-induced intoxicated rats reduced significantly the activity of transaminases and the levels of the markers for kidney function as follows: AST (by $24 \%$ ), ALT (by $14 \%$ ), urea (by $27 \%$ ) and creatinine (by $21 \%$ ), compared to the $\mathrm{CCl}_{4}$ alone group (Fig. 3). These effects were similar to the effect of silymarin which decreased AST by $36 \%$, ALT by $20 \%$, urea by $25 \%$ and creatinine level by $27 \%$, compared to the $\mathrm{CCl}_{4}$-alone group $(p<0.05)$. 
a)

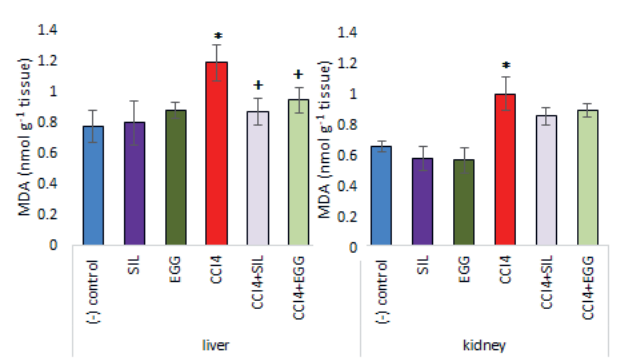

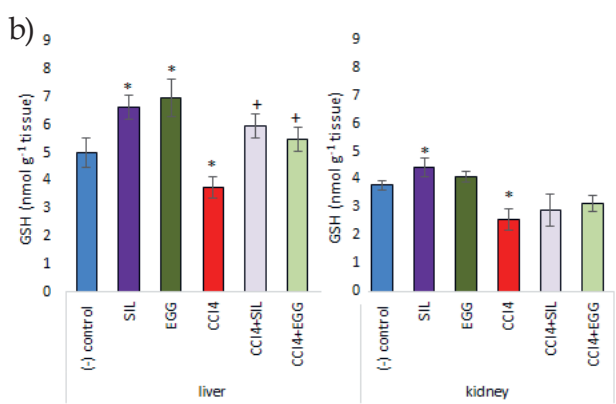

Fig. 2. Effects of EGG and silymarin administered alone and after $\mathrm{CCl}_{4}$ intoxication, on hepatic and renal: a) MDA and b) GSH levels. Results are expressed as mean \pm SD $(n=6)$.

a) 350

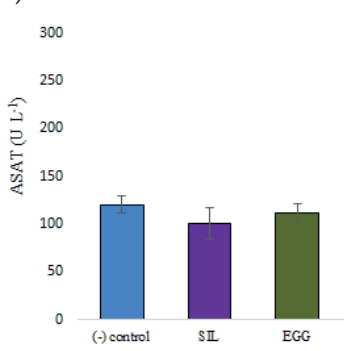

c)$$
\text { c) } 14
$$$$
\text { 孚 } 8
$$

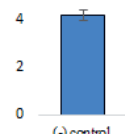

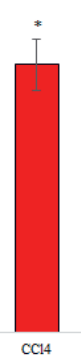
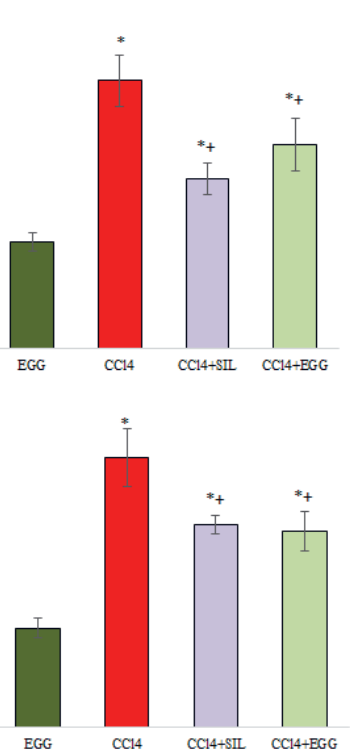

b) ${ }^{140}$

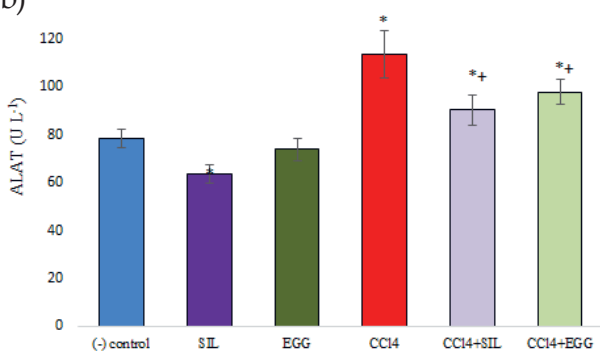

d) 120

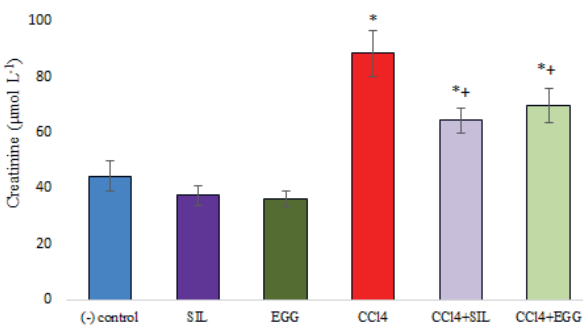

Fig. 3. Effects of EGG and silymarin, administered alone and after $\mathrm{CCl}_{4}$ intoxication, on serum biochemical markers: a) AST, b) ALT, c) urea, and d) creatinine. Results are expressed as mean $\pm \operatorname{SD}(n=6)$.

Herein, the presence of a variety of 2"-O-pentosyl-6-C-hexosyl-apigenin/luteolin/ methylluteolin and their acetyl- and methoxycinnamoyl-derivatives together with $C$-glycosyl-flavones could be associated with the protective effect of EGG. Huang et al. (14) reported a significant protective effect and improvement of the liver function by the administration of isoorientin-2"-O- $\alpha$-L-arabinopyranosyl (IOA) isolated from G. elegans. The authors found decreased levels of ALT, AST, ALP, c-glutamyltransferase, interleukin- 6 and tumor necrosis factor in alcohol-induced liver injury in rats. They showed that IOA effec- 
tively reduced pathological tissue damage, as was found in the present study. Research on the protective mechanisms showed that IOA can inhibit $\mathrm{CCl}_{4}$-induced hepatic damages, due to its radical scavenging action, antioxidant activity, and modulation of NF- $\kappa B$ and TGF- $\beta 1 /$ Smad signaling pathways $(15,16)$.

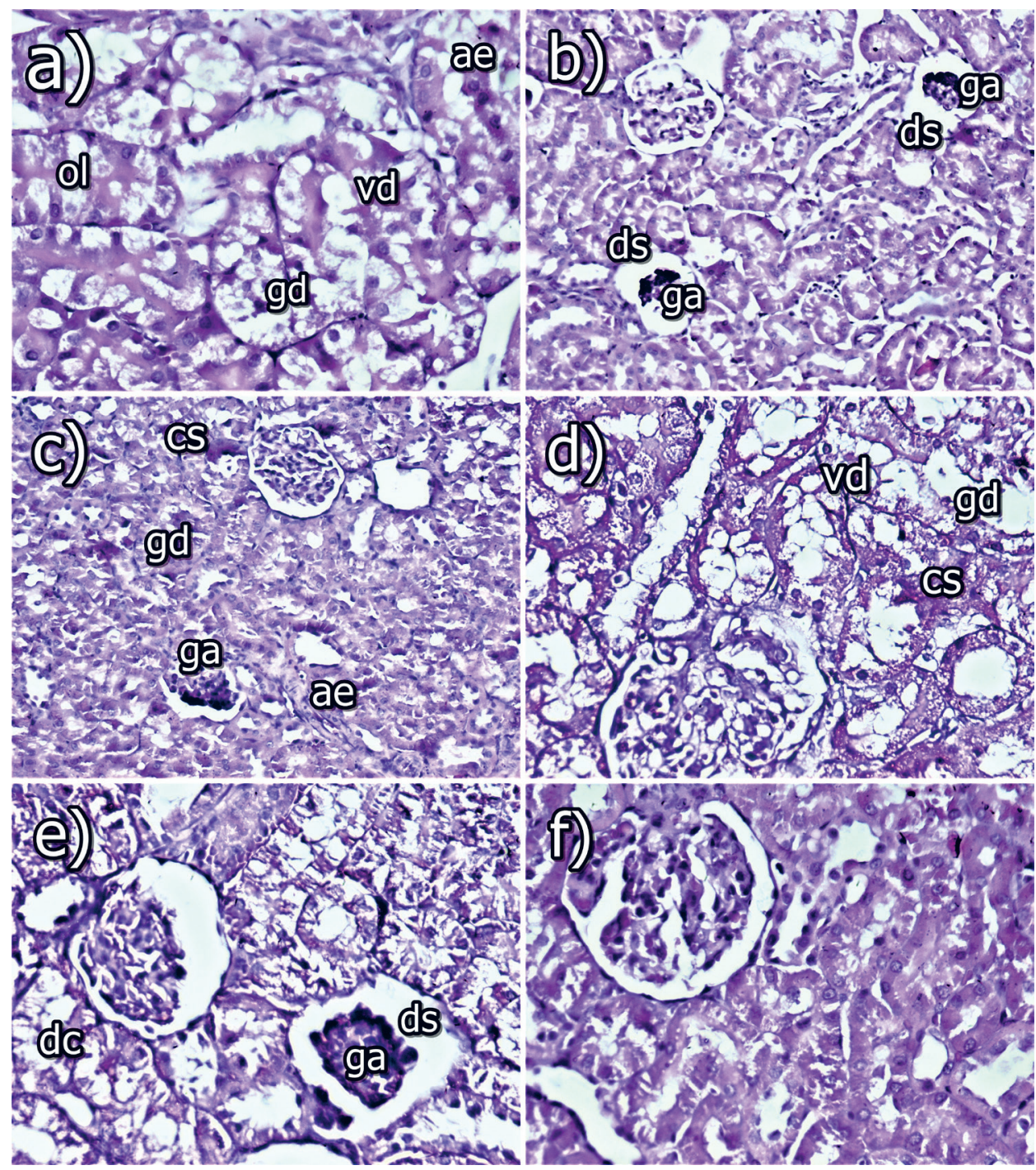

Fig. 4. Histopathological photomicrographs showing the $\mathrm{CCl}_{4}$-induced alterations and the effects of EGG and silymarin in renal tissues: a) and b) $\mathrm{CCl}_{4}$-damaged tubules, c) combination of $\mathrm{CCl}_{4}$ and silymarin, d) and e) combination of $\mathrm{CCl}_{4}$ and EGG, f) normal kidney from the control group. a), d)-f) $\mathrm{HE} \times 300, b), c) \mathrm{HE} \times 200$. 
B. Dimitorva et al:: Molecular networking-assisted flavonoid profile of Gypsophila glomerata extract in relation to its protective effects on carbon tetrachloride-induced hepatorenal damage in rats, Acta Pharm. 72 (2022) 59-77.

The more pronounced antioxidant ability of the $C$-glycosyl flavonoids in comparison with the $O$-glycosyl flavonoids was reported by Barreca et al. (39). Moreover, homoorientin, orientin, isovitexin and vitexin also possess some beneficial activities such as anti-inflammatory, antibacterial, antiproliferative, antimutagenic and anticarcinogenic (40), which could add significantly to the above-mentioned protective effects of the flavonoids.
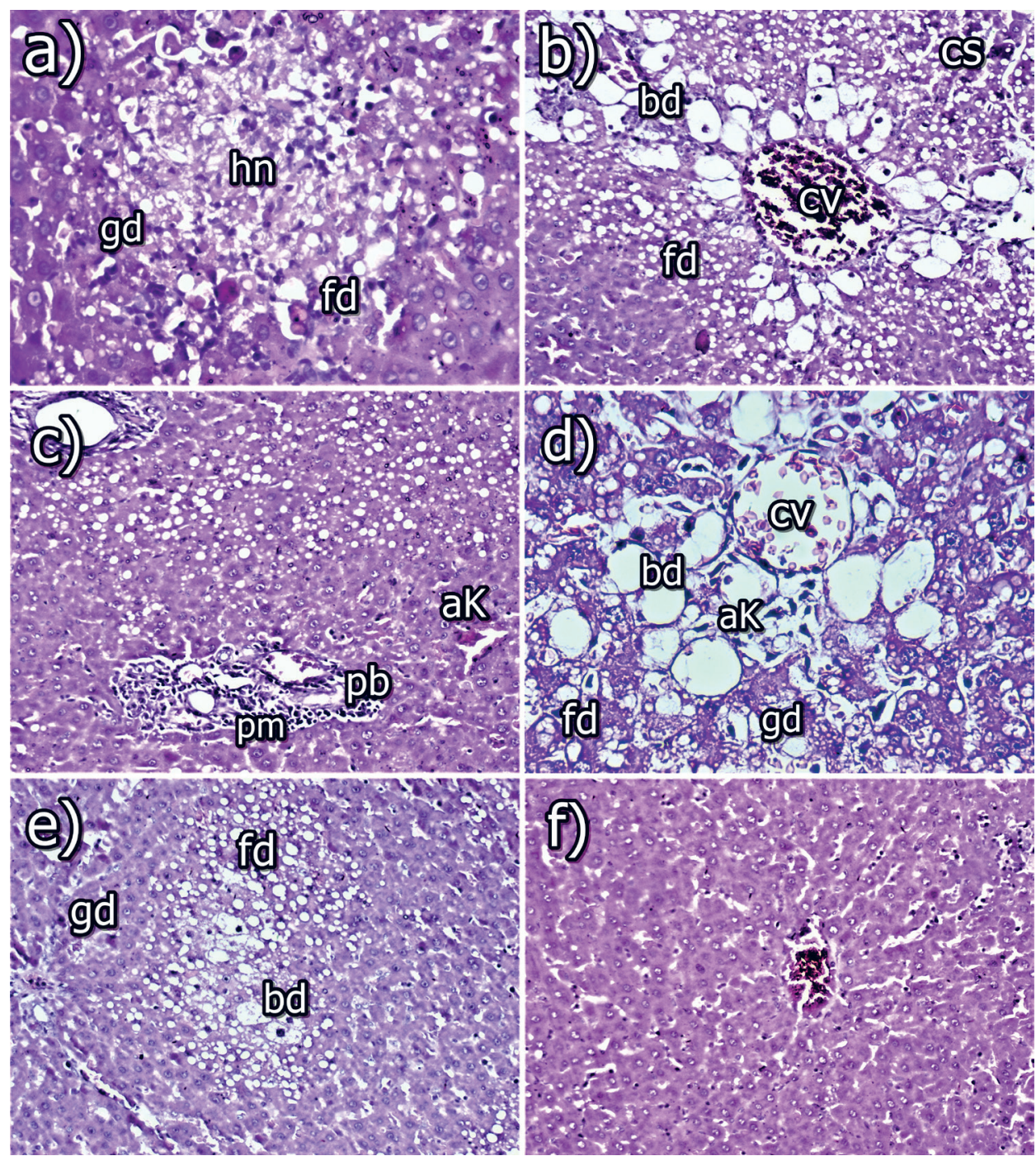

Fig. 5. Histopathological photomicrographs showing the $\mathrm{CCl}_{4}$-induced alterations and the effects of EGG and silymarin in hepatic tissues: a), b) and c) damaged hepatocytes in the $\mathrm{CCl}_{4}$ group, d) combination of $\mathrm{CCl}_{4}$ and silymarin, e) combination of $\mathrm{CCl}_{4}$ and EGG, f) control rat hepatocytes. a) and d) $\mathrm{HE} \times 300, \mathrm{~b}), \mathrm{c}) \mathrm{e}), \mathrm{f}) \mathrm{HE} \times 200$. 


\section{Macroscopical and histopathological assessment}

Macroscopical examination at slaughter time revealed that liver and kidney volume was significantly larger, with yellowish colour in the $\mathrm{CCl}_{4}$-exposed group compared with the control group. In other experimental groups, the color and the size of the examined organs were relatively preserved and similar in appearance/morphology to the control.

Histological photomicrographs provided a direct assessment of the effects of the investigated compounds on the kidneys and livers (Figs. 4 and 5). The kidney and liver tissues in the control rats showed normal architecture. No pathological changes were observed in the glomeruli or in the tubular kidney epithelium (Fig. 4f), nor in the hepatocytes (Fig. 5f) in the control animals.

Renal histopathology from $\mathrm{CCl}_{4}$-treated rats showed moderate degenerative changes in the tubular epithelium of the renal cortex, e.g., cloudy swelling, granular (gd) and/or vacuolar degeneration (vd). The tubular epithelial cells were often swollen and tubular lumen was diminished and sometimes occluded (ol) by the enlarged epithelium (ae) (Fig. 4a). Some of the vacuolated epithelial cells were with foamy appearance, whereas other epithelial cells were completely necrotized. Some glomeruli showed mild dilatation of Bowman's space (ds) and partial glomerular atrophy, whereas others were with total atrophy (ga) or sclerosis (Fig. 4b). Mild congestion of capillary loops or peritubular capillaries was also observed in some places and activation of capillary endothelium (ae) was present. Small foci of mononuclear proliferation in the renal interstitium were also visible in some areas. These alterations were also found in the study of Okolo et al. (41) who showed that the administration of $\mathrm{CCl}_{4}$ markedly disrupted the normal architecture of the kidney cell by degenerating the tubules and collapsing the glomerulus.

The same scientific group (41) found that the hepatocytes of $\mathrm{CCl}_{4}$-treated rats showed proliferation of bile duct epithelium with dilated and congested sinusoids. Similar findings have also been found in this study. In the liver, there was a strong fatty (fd) and granular degeneration (gd), which was more pronounced in the central part of the lobules, where disorderly hepatocyte cords were found (Fig. 5a). Cloudy swelling (cs) (Fig. 5b) of some hepatocytes and small hepatocellular necroses (hn) (Fig. 5a) were found mainly in the central parts of the lobules. A strong ballooning degeneration (bd) of hepatocytes was observed in the central parts of the lobules (Fig. 5b). A mild proliferation of mononuclear cells and/or connective tissue (pm) and/or proliferation of bile ducts (pb) was observed in Glisson's triangles. A small cluster of macrophages or activated Kupffer cells (aK) were often found in these proliferates (Fig. 5c). Part of the necroses had infiltrated with inflammatory mononuclear cells or single macrophages. Mild congestion of vessels (cv) was also seen, e.g., V. centralis (Fig. 5b).

In the kidneys of rats treated with $\mathrm{CCl}_{4}$ and EGG, there were slight to moderate degenerative changes (dc) in the tubular epithelium of the renal cortex, e.g., cloudy swelling (cs), granular (gd) and/or vacuolar degeneration (vd) (Fig. 4d). The tubular epithelial cells often appeared swollen and thereby obscured the tubular lumen. A few glomeruli showed mild dilatation of Bowman's space (ds), and partial glomerular atrophy (ga) (Fig. 4e), whereas total atrophy or sclerosis of glomeruli was rarely seen. Mild congestion of capillary loops or peritubular capillaries was rarely noticed in some places. The capillary endothelium of peritubular capillaries was activated. Small foci of mononuclear proliferation in the renal interstitium were also seen in some areas. 
There was a moderate fatty (fd) and/or granular degeneration (gd) in the livers of these animals, which was well visible in the central part of the lobules. In some places, cloudy swelling of some hepatocytes was observed. A ballooning degeneration (bd) of hepatocytes was seen in part of the hepatocytes in the central parts of some lobules (Fig. 5e), while small hepatocellular necroses infiltrated with macrophages or leucocytes were rarely found. A mild proliferation of mononuclear cells, and/or connective tissue and/or proliferation of bile ducts were observed in the Glisson's triangles. A small cluster of macrophages or activated Kupffer $(\mathrm{aK})$ cells were often found in these proliferates. A mild to moderate congestion of vessels was also seen, e.g., V. centralis.

Gypsophila elegans isoorientin-2"-O- $\alpha$-L-arabinopyranosyl (GEI) ameliorates porcine serum-induced immune liver injury as evidenced by decreased pathological damages (16). These researchers found that GEI significantly alleviated liver injury and collagen accumulation by reducing hepatocyte loosening, fatty degeneration, portal inflammation and necrosis, which is in accordance with the results of this study.

In the rats treated with $\mathrm{CCl}_{4}$ and silymarin, there were slight degenerative changes in the tubular epithelium of the renal cortex, e.g., cloudy swelling (cs), granular and/or vacuolar degeneration (gd). The tubular epithelial cells often appeared swollen and the tubular lumen was diminished by the enlarged epithelium. A few glomeruli showed mild dilatation of Bowman's space and partial glomerular atrophy (ga) (Fig. 4c), whereas total atrophy or sclerosis of glomeruli was rarely seen. Mild congestion of capillary loops or peritubular capillaries was rarely seen in some places as well as activation of capillary endothelium (ae) was presented. In some areas, small foci of mononuclear proliferation in the renal interstitium were also seen.

The well-known protective effect of silymarin has been reported previously in rat cisplatin-induced renal toxicity (42), as well as in dog gentamicin-induced renal damages (43) and in alloxan-induced diabetic nephropathy too (6). In our experimental study, the protective effect of silymarin was confirmed with the decreased levels of creatinine and urea (Figs. 3c,d) along with the less pronounced degenerative damages in epithelial cells of renal tubules (Fig. 4c).

In the group where rat livers were treated with $\mathrm{CCl}_{4}$ and silymarin, there was moderate fatty (fd) and granular degeneration (gd), which was more pronounced in the central area of the lobules. Cloudy swelling of some hepatocytes was observed in some places. A ballooning degeneration (bd) of hepatocytes was rarely seen in the central parts of some lobules, and small hepatocellular necroses infiltrated with macrophages were rarely found. A mild proliferation of mononuclear cells and/or connective tissue and/or proliferation of bile ducts were seen in Glisson's triangles. A small cluster of macrophages or activated Kupffer cells (aK) were often found in these proliferates. Mild congestion of vessels (cv) was also noticed, e.g., V. centralis (Fig. 5d).

The protective effect of silymarin is reported due to the observed decrease in lipid peroxidation and the increase in endogenous antioxidants, which are responsible for the integrity of the plasma membrane and, therefore, counteract the leakage of some target enzymes $(44,45)$. In this study, the 7-day pretreatment with silymarin and EGG before $\mathrm{CCl}_{4}$ intoxication aimed to stabilize the cell membranes and thus prevent enzyme leakage. Freitag et al. (46) reported that silymarin treatment has restored the hepatocyte functional and histopathological alterations induced by paracetamol in normotensive and hypertensive animals. In another study of experımental obstructıve jaundice model, the enlargement of 
hepatocytes, dilatation of canaliculi and the edema regressed in livers in the silymarin-treated group was reported (47).

No pathological changes were seen in the glomeruli or in the tubular kidney epithelium of rats treated only with silymarin, nor were pathological changes in hepatocytes of their livers observed. A mild fatty degeneration and a mild mononuclear proliferation were found in the liver only in one of the rats treated with silymarin.

There was a slight mononuclear cell proliferation in the renal interstitium of two rats treated with EGG alone. Degenerative changes, which were shown to be not significant, were found in some hepatocytes in only two rats. A minor proliferation of mononuclear cells, activation of Kupffer cells and slight hyperaemia of sinusoidal capillaries were observed in the same two rats.

The analysis of the results showed that histopathological and biochemical changes were strongest in rats exposed to $\mathrm{CCl}_{4}$ without any supplemental treatment, followed by rats treated additionally with EGG and those treated with silymarin, whereas scarce changes or no changes were seen in control rats and in rats treated with EGG or silymarin only. It seems that the G. glomerata extract (EGG) has a good protective effect against the toxic effects of $\mathrm{CCl}_{4}$ on the liver and kidneys, which is similar to that of silymarin.

\section{CONCLUSIONS}

In summary, twenty-two flavonoid $C_{-}, \mathrm{O}$ - and $\mathrm{C}, \mathrm{O}$-glycosides were dereplicated or tentatively annotated in the G. glomerata aerial parts extract including nine flavonoids previously undescribed in the literature. In this study, molecular networking provides efficient tool for the annotation of new flavonoids in the genus Gypsophila: O-hexuronosyl-(2"pentosyl-6-C-hexosyl)-apigenin (4), 2"-(methoxycinnamoylpentosyl)-6-C-hexosyl-apigenin (5), 2"- (methoxycinnamoyl-acetylpentosyl)-6-C-hexosyl)-apigenin (7), 2"-O-diacetylpentosyl-6-C-hexosyl-methylluteolin (9), 6-C-hexosyl-methylluteolin (18), 2"-methoxycinnamoyl-6-C-hexosyl-apigenin (19), 2"-O-pentosyl-6-C-hexosyl-luteolin (20), 2"-O-(acetylpentosyl)6-C-hexosyl-luteolin (21) and 2"-O-(diacetylpentosyl)-6-C-hexosyl-luteolin (22).

The observed hepatorenal protective effects of G. glomerata could be attributed to flavonoids, notably to the major flavonoids in the chromatographic profile: 2"-O-pentosyl-6$C$-hexosyl-apigenin/luteolin/methylluteolin $(\mathbf{1}, \mathbf{1 6}, \mathbf{2 0})$ and diacetylated derivative 3 . However, further investigations on the detailed mechanisms of action are needed.

Acknowledgements. - The authors thank Dr. Nisha Singh for English editing. Supplementary material available on request.

\section{REFERENCES}

1. M. Ekor, The growing use of herbal medicines: issues relating to adverse reactions and challenges in monitoring safety, Front. Pharmacol. 4 (2014) Article ID 177 (10 pages); https://doi.org/10.3389/ fphar.2013.00177

2. R. F. F. de Araújo, D. B. G. Martins and M. A. C. S. M. Borba, Oxidative Stress and Disease, in A Master Regulator of Oxidative Stress - The Transcription Factor Nrf2 (Eds. J. A. Morales-Gonzalez, A. MoralesGonzález and E. O. Madrigal-Santillan), IntechOpen, Rijeka 2016. 
3. T. Senoner and W. Dichtl, Oxidative stress in cardiovascular diseases: Still a therapeutic target?, Nutrients 11 (2019) Article ID 2090 (25 pages); https://doi.org/10.3390\%2Fnu11092090

4. Y. Kayama, U. Raaz, A. Jagger, M. Adam, I. N. Schellinger, M. Sakamoto, H. Suzuki, K. Toyama, J. M. Spin and P. S. Tsao, Diabetic cardiovascular disease induced by oxidative stress, Int. J. Mol. Sci. 16 (2015) 25234-25263; https://doi.org/10.3390/ijms161025234

5. C. Forni, F. Facchiano, M. Bartoli, S. Pieretti, A. Facchiano, D. D’Arcangelo, S. Norelli, G. Valle, R. Nisini, S. Beninati, C. Tabolacci and R. N. Jadeja, Beneficial role of phytochemicals on oxidative stress and age-related diseases, Biomed. Res. Int. 2019 (2019) Article ID 8748253 (17 pages); https://doi. org/10.1155/2019/8748253

6. J. Teixeira, D. Chavarria, F. Borges, L. Wojtczak, M. R. Wieckowski, A. Karkucinska-Wieckowska and P. J. Oliveira, Dietary polyphenols and mitochondrial function: role in health and disease, Curr. Med. Chem. 26 (2019) 3376-3406; https://doi.org/10.2174/0929867324666170529101810

7. R. Saller, J. Melzer, J. Reichling, R. Brignoli and R. Meier, An updated systematic review of the pharmacology of silymarin, Forsch. Komp. Klas. Nat. 14 (2007) 70-80; https://doi.org/10.1159/000100581

8. E. Shaker, H. Mahmoud and S. Mnaa, Silymarin, the antioxidant component and Silybum marianum extracts prevent liver damage, Food Chem. Toxicol. 48 (2010) 803-806.

9. C. Soto, J. Pérez, V. García, E. Uría, M. Vadillo and L. Raya, Effect of silymarin on kidneys of rats suffering from alloxan-induced diabetes mellitus, Phytomedicine 17 (2010) 1090-1094; https://doi. org/10.1016/j.phymed.2010.04.011

10. S. D. Stoev, P. Njobeh, I. Zarkov, T. Mircheva, D. Zapryanova, S. Denev and B. Dimitrova, Selected herbal feed additives showing protective effects against ochratoxin A toxicosis in broiler chicks, World Mycotoxin J. 12 (2019) 257-268; https://doi.org/10.3920/WMJ2019.2432

11. M. Bahmani, H. Shirzad, S. Rafieian and M. Rafieian-Kopaei, Silybum marianum: Beyond hepatoprotection, Evid-Based Complement. Alternat.Med.20(2015)292-301; https://doi.org/10.1177/2156587215571116

12. S. K. Katiyar, Silymarin and skin cancer prevention: anti-inflammatory, antioxidant and immunomodulatory effects, Int. J. Oncol. 26 (2005) 169-176.

13. Q. Chen, J.-G. Luo and L.-Y. Kong, Triterpenoid saponins from Gypsophila altissima L., Chem. Pharm. Bull. 58 (2010) 412-414; https://doi.org/10.1248/cpb.58.412

14. Q. F. Huang, S. J. Zhang, L. Zheng, M. Liao, M. He, R. Huang, L. Zhuo and X. Lin, Protective effect of isoorientin-2"-O- $\alpha$-l-arabinopyranosyl isolated from Gypsophila elegans on alcohol induced hepatic fibrosis in rats, Food Chem. Toxicol. 50 (2012) 1992-2001; https://doi.org/10.1016/j.fct.2012.03.044

15. X. Lin, Y. Chen, S. Lv, S. Tan, S. Zhang, R. Huang, L. Zhuo, S. Liang, Z. Lu and Q. Huang, Gypsophila elegans isoorientin attenuates $\mathrm{CCl}_{4}$-induced hepaticfibrosis in rats via modulation of NF- $\kappa \mathrm{B}$ and TGF-31/Smad signaling pathways, Int. Immunopharmacol. 28 (2015) 305-312; https://doi.org/10.1016/j. intimp.2015.06.021

16. F. Bai, Q. Huang, J. Wei, S. Lv, Y. Chen, C. Liang, L. Wei, Z. Lu and X. Lin, Gypsophila elegans isoorientin-2 "-O- $\alpha$-1-arabinopyranosyl ameliorates porcine serum-induced immune liver fibrosis by inhibiting NF- $\mathrm{B}$ signaling pathway and suppressing HSC activation, Int. Immunopharmacol. 54 (2018) 60-67; https://doi.org/10.1016/j.intimp.2017.10.028

17. V. Vitcheva, R. Simeonova, I. Krasteva, M. Yotova, S. Nikolov and M. Mitcheva, Hepatoprotective effects of saponarin, isolated from Gypsophila trichotoma Wend. on cocaine-induced oxidative stress in rats, Redox Rep. 16 (2011) 56-61; https://doi.org/10.1179/174329211x12989133691530

18. D. Zheleva-Dimitrova, G. Zengin, V. Balabanova, Y. Voynikov, V. Lozanov, I. Lazarova and R. Gevrenova, Chemical characterization with in vitro biological activities of Gypsophila species, J. Pharm. Biomed. Anal. 155 (2018) 56-69; https://doi.org/10.1016/j.jpba.2018.03.040

19. R. Simeonova, M. Kondeva-Burdina, V. Vitcheva, I. Krasteva, V. Manov and M. Mitcheva, Protective effects of the apigenin-O/C-diglucoside saponarin from Gypsophila trichotoma on carbone tetrachlo- 
ride-induced hepatotoxicity in vitro/in vivo in rats, Phytomedicine 21 (2014) 148-154; https://doi. org/10.1016/j.phymed.2013.07.014

20. R. Simeonova, V. Vitcheva, M. Kondeva-Burdina, I. Krasteva, V. Manov and M. Mitcheva, Hepatoprotective and antioxidant effects of saponarin, isolated from Gypsophila trichotoma Wend. on paracetamol-induced liver damage in rats, Biomed. Res. Int. 2013 (2013) Article ID 757126; https://doi. org/10.1155/2013/757126

21. R. Gevrenova, K. Bardarov, S. Bouguet-Bonnet, Y. Voynikov, V. Balabanova, D. Zheleva-Dimitrova and M. Henry, A new liquid chromatography-high resolution Orbitrap mass spectrometry-based strategy to characterize glucuronide oleanane-type triterpenoid carboxylic acid 3,28-O-bidesmosides (GOTCAB) saponins. A case study of Gypsophila glomerata Pall ex M. B. (Caryophyllaceae), J. Pharm. Biomed. Anal. 159 (2018) 567-581; https://doi.org/10.1016/j.jpba.2018.07.041

22. F. Ferreres, A. Gil-Izquierdo, P. B. Andrade, P. Valentão and F. Tomás-Barberán, Characterization of C-glycosyl flavones O-glycosylated by liquid chromatography-tandem mass spectrometry, J. Chromatogr. A. 1161 (2007) 214-223; https://doi.org/10.1016/j.chroma.2007.05.103

23. W. Nie, J.-G. Luo and L.-Y. Kong, C-glycosyl flavonoids from the aerial part of Gypsophila pacifica, Chin. J. Nat. Med. 8 (2010) 250-252; https://doi.org/10.3724/SP.J.1009.2010.00250

24. F. M. Zhang, Z. G. Tai, L. Cai, Y. B. Yang, F. Li and Z. T. Ding, Flavonoids from Gypsophila elegans and their antioxidant activities, J. Yunnan Univ. Nat. Sci. 33 (2011) 93-95.

25. Council of Europe. European Convention for the Protection of Vertebrate, Animals Used for Experimental and other Scientific Purposes, CETS No. 123, 1991 [displayed 30 May 2007]; https://ec.europa.eu/ world/agreements/downloadFile.do?fullText=yes\&treaty TransId=1346; last access date Nov 4, 2020

26. P. V. Habbu, R. A. Shastry, K. M. Mahadevan, H. Joshi and S. K. Das, Hepatoprotective and antioxidant effects of Argyreia speciosa in rats, Afr. J. Tradit. Complement. Altern. Med. 5 (2008) 158-164; https:// doi.org/10.4314\%2Fajtcam.v5i2.31268

27. T. H. Ahn, Y. S. Yang, J. C. Lee, C. J. Moon, S. H. Kim, W. Jun, S. C. Park and J. C. Kim, Ameliorative effects of pycnogenol on carbon tetrachloride-induced hepaticoxidative damage in rats, Phytother. Res. 21 (2007) 1015-1019; https://doi.org/10.1002/ptr.2146

28. European Parliament and of the Council, Directive 2010/63/EU of the European Parliament and of the Council of 22 September 2010 on the protection of animals used for scientific purposes, Off. J. Eur. Union (2010) L 276/33-79; https://eur-lex.europa.eu/LexUriServ/LexUriServ.do?uri=OJ:L:2010:276:0033 :0079:en:PDF; last access date Nov 4, 2020

29. J. L. Wolfender, P. M. Allard, M. Kubo and E. F. Queiroz, Metabolomics Strategies for the Dereplication of Polyphenols and Other Metabolites, in Recent Advances in Polyphenol Research (Eds. H. Halbwirth, K. Stich, V. Cheynier and S. Quideau), $1^{\text {st }}$ ed, Wiley, Hoboken (NJ) 2019, pp. 183-205.

30. M. Wang, J. J. Carver, W. Phelan, L. M. Sanchez, N. Garg, Y. Peng, D. D. Nguyen, J. Watrous, C. A. Capono, T. Luzzatto-Knaan, C. Porto, A. Bouslimani, A. V. Melnik, M. J. Meehan, W.-T. Liu, M. Crüsemann, P. D. Boudreau, E. Esquenazi, M. Sandoval-Calderón, R. D. Kersten, L. A. Pace, R. A. Quinn, K. R. Duncan, C.-C. Hsu, D. J. Floros, R. G. Gavilan, K. Kleigrewe, T. Northen, R. J. Dutton, D. Parrot, E. E. Carlson, B. Aigle, C. F. Michelsen, L. Jelsbak, C. Sohlenkamp, P. Pevzner, A. Edlund, J. McLean, J. Piel, B. T. Murphy, L. Gerwick, C.-C. Liaw, Y.-L. Yang, H.-U. Humpf, M. Maansson, R. A. Keyzers, A. C. Sims, A. R. Johnson, A. M. Sidebottom, B. E. Sedio, A. Klitgaard, C. B. Larson, C. A. Boya, D. Torres-Mendoza, D. J. Gonzalez, D. B. Silva, L. M. Marques, D. P. Demarque, E. Pociute, E. C. O'Neill, E. Briand, E. J. N. Helfrich, E. A. Granatosky, E. Glukhov, F. Ryffel, H. Houson, H. Mohimani, J. J. Kharbush, Y. Zeng, J. A. Vorholt, K. L. Kurita, P. Charusanti, K. L. McPhail, K. F. Nielsen, L. Vuong, M. Elfeki, M. F. Traxler, N. Engene, N. Koyama, O. B. Vining, R. Baric, R. R. Silva, S. J. Mascuch, S. Tomasi, S. Jenkins, V. Macherla, T. Hoffman, V. Agarwal, P. G. Williams, J. Dai, R. Neupane, J. Gurr, A. M. C. Rodríguez, A. Lamsa, C. Zhang, K. Dorrestein, B. M. Duggan, J. Almaliti, P.-M. Allard, P. Phapale, L.-F. Nothias, T. Alexandrov, M. Litaudon, J.-L. Wolfender, J. E. Kyle, T. O. Metz, T. Peryea, D.-T. Nguyen, D. VanLeer, P. Shinn, A. Jadhav, R. Müller, K. M. Waters, W. Shi, X. Liu, L. Zhang, R. 
Knight, P. R. Jensen, B. O. Palsson, K. Pogliano, R. G. Linington, M. Gutiérrez, N. P. Lopes, W. H. Gerwick, B. S. Moore, P. C. Dorrestein and N. Bandeira, Sharing and community curation of mass spectrometry data with global natural products social molecular networking, Nat. Biotechnol. 34 (2016) 828-837; https://doi.org/10.1038/nbt.3597

31. A. H. Polizio and C. Peña, Effects of angiotensin II type 1 receptor blockade on the oxidative stress in spontaneously hypertensive rat tissues, Regul. Pept. 128 (2005) 1-5; https://doi.org/10.1016/j.regpep.2004.12.004

32. E. A. Bump, Y. C. Taylor and M. J. Brown, Role of glutathione in the hypoxic cell cytotoxicity of misonidazole, Cancer Res. 43 (1983) 997-1002.

33. R. Gevrenova, D. Zheleva-Dimitrova, V. Balabanova, Y. Voynikov, K. I. Sinan, M. F. Mahomoodally and G. Zengin, Integrated phytochemistry, bio-functional potential and multivariate analysis of Tanacetum macrophyllum (Waldst. \& Kit.) Sch. Bip. and Telekia speciosa (Schreb.) Baumg. (Asteraceae), Ind. Crops Prod. 155 (2020) Article ID 112817; https://doi.org/10.1016/j.indcrop.2020.112817

34. A. A. Rahmat, F. A. Dar and I. M. Choudhary, Protection of $\mathrm{CCl}_{4}$-Induced liver and kidney damage by phenolic compounds in leaf extracts of Cnestis ferruginea (de Candolle), Pharmacog. Res. 6 (2014) 19-28; https://doi.org/10.4103\%2F0974-8490.122913

35. A. S. M. Al Amin and R. G. Menezes, Carbon tetrachloride toxicity, StatPearls [Internet], StatPearls Publishing, Treasure Island (FL) 2020; https://www.ncbi.nlm.nih.gov/books/NBK562180/

36. S. Sahreen, M. R. Khan and R. A. Khan, Hepatoprotective effects of methanol extract of Carissa opaca leaves on $\mathrm{CCl}_{4}$-induced damage in rat, BMC Complement. Altern. Med. 11 (2011) Article ID 48 (9 pages); https://doi.org/10.1186/1472-6882-11-48

37. M. Ogeturk, I. Kus, N. Colakoglu, I. Zararsiz, N. Ilhan and M. Sarsilmaz, Caffeic acid phenyl ester protects kidneys against carbon tetrachloride toxicity in rats, J. Ethnopharmacol. 97 (2005) 273-280.

38. F. Ozturk, M. Ucar, I. C. Ozturk, N. Vardi and K. Batcioglu, Carbon tetrachloride induced nephrotoxicity and protective effect of betaine in Sprague-Dawley rats, Urology 62 (2003) 353-356.

39. D. Barreca, E. Bellocco, C. Caristi, U. Leuzzi and G. Gattuso, Distribution of C-and O-glycosyl flavonoids, (3-hydroxy-3-methylglutaryl)glycosyl flavanones and furocoumarins in Citrus aurantium L. juice, Food Chem. 124 (2011) 576-582; https://doi.org/10.1016/j.foodchem.2010.06.076

40. H. F. dos Santos, J. F. Campos, C. M. dos Santos, J. B. Perrella Balestieri, D. B. Silva, C. A. Carollo, K. de Picoli Souza, L. M. Estevinho and E. L. dos Santos, Chemical profile and antioxidant, anti-inflammatory, antimutagenic and antimicrobial activities of geopropolis from the stingless bee Melipona orbigny, Int. J. Mol. Sci. 18 (2017) Article ID 953 (18 pages); https://doi.org/10.3390\%2Fijms18050953

41. K. O. Okolo, I. M. Siminialayi and O. E. Orisakwe, Carbon tetrachloride induced hepatorenal toxicity in rats: possible protective effects of wild Pleurotus tuber-regium, Clin. Phytosci. 3 (2017) Article ID 2 (7 pages); https://doi.org/10.1186/s40816-016-0040-5

42. G. Karimi, M. Ramezani and Z. Tahoonian, Cisplatin nephrotoxicity and protection by milk thistle extract in rats, Evid-Based Complement. Alternat. Med. 2 (2005) 383-386; https://doi.org/10.1093/ecam/ neh103

43. H. N. Varzi, S. Esmailzadeh, H. Morovvati, R. Avizeh, A. Shahriari and M. E. Givi, Effect of silymarin and vitamin E on gentamicin-induced nephrotoxicity in dogs, J. Vet. Pharmacol. Ther. 30 (2007) 477481; https://doi.org/10.1111/j.1365-2885.2007.00901.x

44. G. Upadhyay, M. N. Tiwari, O. Prakash, A. Jyoti, R. Shanker and M. P. Singh, Involvement of multiple molecular events in pyrogallol-induced hepatotoxicity and silymarin-mediated protection: Evidence from gene expression profiles, Food Chem. Toxicol. 48 (2010) 1660-1670; https://doi.org/10.1016/j. fct.2010.03.041

45. G. Karimi, M. Vahabzadeh, P. Lari, M. Rashedinia and M. Moshiri, Silymarin, a promising pharmacological agent for treatment of diseases, Iranian J. Basic Med. Sci. 14 (2011) 308-317. 
46. A. F. Freitag, G. F. Cardia, B. A. da Rocha, R. P. Aguiar, F. M. de Souza Silva-Comar, R. A. Spironello, R. Grespan, S. M. Caparroz-Assef, C. A. Bersani-Amado and R. K. Nakamura Cuman, Hepatoprotective effect of silymarin (Silybum marianum) on hepatotoxicity induced by acetaminophen in spontaneously hypertensive rats, Evid-Based Complement. Alternat. Med. 2015 (2015) Article ID 538317 (8 pages); https://doi.org/10.1155/2015/538317

47. A. K. Onalan, S. Tuncal, S. Kilicoglu, S. Celepli, E. Durak, B. Kilicoglu, E. Devrim, A. Mutlu Barlas and K. Kismet, Effect of silymarin on oxidative stress and liver histopathology in experimental obstructive jaundice model, Acta Cir. Bras. 31 (2016) 801-806; https://doi.org/10.1590/s0102-865020160120000004 